\title{
DOS CRIMES CONTRA A ORDEM TRIBUTARIA
}

\author{
Prof. Titular L. A. MACHADO
}

\section{I - INTRODUÇĀO}

1. A existência de censura social - fonte material remota de direito penal $^{1}$; WELZEL chega a dizer que é o sentimento coletivo, entendendo inadequada socialmente a conduta, que a faz criminosa ${ }^{2}$ - em relação às ações que visam à sonegação de tributo, é altamente duvidosa. MALINVERNI chega a afirmar que fraudar o fisco é, na Itália, um esporte nacional ${ }^{3}$ com o que concorda SPINELLI ${ }^{4}$. Mas a discussão é inoportuna e inadequada quando a lei, superando-a, desde logo considera a ação como delituosa, cominando-lhe uma sanção penal.

SOLER, vendo a sanção como uma reposição jurídica ao "status quo ante" da infração, divide-a em três categorias: repositivas, reparativas e retributivas ${ }^{5}$. Entende que, em relação às duas primeiras, há uma reposição, seja real, seja simbólica, enquanto que a sanção retributiva implica em um "plus" à reposição ${ }^{6}$. Por isso define o direito penal como "o conjunto de normas dotadas de sanções retributivas" 7 .

Desde esse enfoque, não há negar que o direito, quando sanciona as infrações às suas normas com um "plus" retributivo à mera reposição (quer por desvalor de resultado, quer por desvalor de conduta, quer por ambos), será sempre penal.

No crime fiscal alguns veem "direito penal tributário" e, outros, "direito tributário penal". Não me parece próprio, porém, dividir-se o direito penal para fazê-lo, "verbi gratia", administrativo penal, tributário penal, isto é, se o transformando em mero atributo de cada um dos demais ramos do direito.

1. GIUSEPPE BETTIOL, Direito Penal, v. I, p. 103 (trad. do Prof. PAUlO JOSÉ DA COSTA JUNIOR). Também ANIBAL BRUNO e REINHART MAURACH.

2. HANS WELZEL, Derecho Penal Aleman, 1956, p. 63.

3. HELENO CLAUDIO FRAGOSO, Novo Direito Penal Tributário e Econômico, Revista Brasileira de Criminologia e Direito Penal, $n^{0}$. 12, p. 68.

4. "La morale media non sente la riprovazione per la violazione delle leggi tributarie", GUSEPPE SPINELLI, Norme Generali per la Repressione delle Violazione del le Legge Finanziarie, Gufrè, Milano, 1957, p. 3.

5. SEBASTIAN SOLER, Conceito e Objeto do Direito Penal, Revista de Direito Penal, $\mathrm{n}^{\circ} .4$, p. 37.

$6 . V$. nota 5 .

7.V. nota 5 . 
Sendo, de um prisma lógico, sancionador - pois que retribui quando a reposição ou a reparação não são mais possiveis (seja pela impossibilidade fática, homicídio; seja pela social ou ética, furto, estelionato), o direito penal escolhe, no mundo jurídico, as ações que entenda dever tipificar. Assim, na formação do tipo material (a conduta tipicamente formal ilícita), o direito penal elege os bens jurídicos que irá proteger e as condutas que hipoteticamente os ofenderão ${ }^{8}$.

Ora, sancionando os preceitos que escolhe nos demais ramos jurídicos, há sempre "direito penal", embora, às vezes, como reforço de expressão se The agreguem as palavras tributário, administrativo, econômico, financeiro, comercial, etc.. Não é por sancionar-se penalmente a infração ao dever de alimentos (C. Civil, art. 39; C. Penal de 1940, art. 144), dir-se-á haver direito civil penal ou direito penal civil.

Concluo que nem há direito penal tributário, nem direito tributário penal: apenas direito penal. Como, com relação ao estabelecimento da relação obrigacional tributária, há apenas direito tributário.

\section{II - ANTECEDENTES LEGISLATIVOS}

2. O C. Penal de 1969 , no artigo $376^{9}$, tratou da consolidação da Lei no. 4.729, de 14.07.65 (que instituiu os crimes de sonegação fiscal), sob a rubrica "fraude contra o fisco".

Já a Lei no. 4.357, de 16.07.64, no artigo 11, apontava como apropriação indébita a retenção indevida de imposto de renda descontado na fonte e de imposto do selo pago por terceiro. A Lei no. 4.505, de 30. 11. 64, fez aplicar o acima referido artigo 11 (Lei no. 4.357, de 1964), através do artigo 38, aos casos de não recolhimento do imposto do selo registrado e retido. Mas foi a Lei no. 4.729, de 1965, que deu foro de cidadania penal à simulação, depois de os tribunais fulminarem as tentativas de erigi-la em "falsum" e, por isso, ser capaz de configuração dos delitos de falsidade material ou ideológica (cf. Revista dos Tribunais, v. 285, p. 70 ; v. 289, p. 57 e 58; v. 291, p. 151). Essas decisões embasaram-se exatamente na conceituação de documento: "escrito devido a um autor determinado, contendo exposição de fatos ou declaração de vontade, dotado de significação ou relevância jurídica"10.

O Ante-Projeto do Código Penal, parte especial, traz, sob a rubrica "Dos Crimes contra a Ordem Tributária", no Capítulo III do Título XII, os crimes de contrabando ou descaminho (art. 400), contrabando ou descaminho por assimilação (art. 400 , $\S \S 10 ., 20$. e $3^{0}$.) e os novos crimes tributários, intitulados apropriação de imposto (art. 401) e não recolhimento de imposto (art. 401, p. único). Com a entrada em vigor

8. "La antijuridicidad, como pura relación entre un objecto (acción) y el derecho, es una sola en la totalidad del orden juridico", HANS WELZEL, Derecho Penal, p. 58.

9. "Fazer declaração falsa ou omitir declaração sobre rendas, bens ou fatos, ou empregar qualquer outra fraude, para eximir-se, total ou parcialmente, a pagamento de imposto ou taxa, se o montante do tributo sonegado ou a sonegar é superior ao salário mínimo.

10. HELENO CLAUDIO FRAGOSO, Lições de Direito Penal, p. e., v. 4, p. 806. 
dessa parte especial, deixarão de viger, dentre outras, as leis especiais que tratam dos crimes tributários, por força da previsão contida no art. 20. do Ante Projeto de Lei sobre a parte especial do C. Penal.

Este estudo busca analisar os tipos novos contidos no art. $401 \mathrm{e}$ seu parágrafo único, deixando de lado o contrabando e o descaminho, principais (art. 400) e assimilados (art. 400, §§ 10., 20. e 30.).

\section{III - SIMULAÇĀO E FALSIDADE}

3. O Direito romano diferençava "dolus" de "fraus": "accanto a dolus nelle nostri fonti, con significato più specifico e portata più limitata, si pone fraus: qui prevale il riferimento alla concreta azione astuta o maliziosa, tanto che il termine può passare ad indicare lo stesso danno - la pena"11. Essa colocação desaguava inclusive na diferença de tratamento típico: o falso era sempre excluído quando ocorria a simulação. Tratava-se diferentemente o "crimen falsi" e o "stelionatus".

Esse foi, também, o entendimento dos praxistas ${ }^{12}$.

Modernamente duas correntes, partindo de premissas diversas, buscam alcançar o mesmo ponto: não há crime de "falsum" na declaração maliciosa ou omissiva da verdade com relação à comprovação de hipóteses de incidência de tributos. A primeira corrente mantém a distinção entre falsidade e simulação, enquanto a segunda afasta a relevância jurídica e, portanto, o elemento normativo do tipo objetivo (documento), quando inexista o dever de dizer a verdade.

4. Segundo FERRARA, "quelo che si ha di piû́ caractteristico nel negozio simulato è la divergenza intenzionale frà volontà e dichiarazione. L'interno voluto e I'esterno dichiarato sono in oposiozine"13. Tratando da "discordância consciente e consensual, mas não viciosa, entre, de um lado, a vontade e vontade de declaração e, de outro lado, a vontade de conteúdo do ato", VICENTE RĀO dá, como elementos da simulação, "a) - uma declaração contrastante com a vontade das partes; b) - ajustada e produzida consciente e consensualmente; c) entre partes que não querem o conteúdo de seu ato exterior, mas o de estipulações constantes de ressalvas; d) - a ocultação do ato real aos terceiros; e) - a ausência de prejuízo a terceiro, ou de violação da lei"14 ${ }^{\prime \prime}$ Isto é, o ato simulado, "per se", não viola a lei.

Em abono a essa posição, já no terreno específico do direito penal, CARRARA entendia que a simulação jamais conduziria à falsidade, mas tão só ao estelionato ${ }^{15}$. O poder de controle da administração pública

11.CARLO GIOFREDI, I Principi del Diritto Penale Romano, p. 68.

12. V. nota 10 , p. 833.

13. FR ANCESCO FERRARA, Della Simulazione dei Negozi Giuridici, $5^{\text {a }}$. ed., p. 37.

14. VICENTE RAO, Ato Juridico, p. 213.

15. FRANCESCO CARRARA, Programa, § 3.659. 
os atos sujeitos a pagamento de tributos não envolve a fé pública. Asim, quando a simulação é feita para iludir o fisco, não e aplicam as regras da falsidade ${ }^{16}$. "Se o oficial ou funcionário público (que recebe a declaração) está adstrito a averiguar, propriis sensibus, a fidelidade da declaração, o declarante, ainda quando falte à verdade, não cometera ilícito penal' ${ }^{\prime 17}$. Também assim expõe BASILEU GARCIA ${ }^{18}$.

Isso porque a mera declaração, por si só, não prova nada. $O$ autolançamento do imposto de renda não significa a prova definitiva do ganho, para efeito de pagamento do tributo.

5. FRAGOSO, por sua vez, nega à simples mentira a possibilidade de constituir o crime de falsidade, eis que "a própria lei exige que se trate de falsidade praticada em relação a fato juridicamente relevante ${ }^{\prime 18}$, embora não faça distinção entre falsidade e simulação ${ }^{19}$. 0 ilustre professor fundamenta a atipia na não exigência de dizer a verdade, vale dizer, quando "il dichiarante abbia il dovere giuridico di esporre la verità'"20 há crime. Mas MANZINI entende que a simulação afasta o dever jurídico de expor a verdade: "poichè l'atto è destinato a provare la verità soltanto di quei fatti che l'attestante hà il dovere giuridico di esporre veridicamente, cosi rimane esclusa della disposizione dell articolo 483 la "simulazione di un negozio giuridico" o altre dichiarazione fraudolente di "volantà" e non di verità. In questi casi non vi è falsità documentale (quando non sia applicabile I'art. 482), bensi, eventualmente, truffa o altro reato' ${ }^{\prime 21}$. Esse entendimento é compartilhado por PISAPIA, ao fixar a relevância jurídica do documento exatamente na existência do "dovere giuridico di attestare il vero" 22 .

6. Em resumo: o ato sujeito a exame pelo poder público como condição de validade e a simulação, esta entendida como "a atividade desenvolvida pelas partes para realizarem o negócio simulado" 23 , não tipificam o crime de falsidade. Aliás, a simulação, tal como vem definida, de forma casuísta, pelo art. 102 do Código Civil, desde que não erigida em crime pelo desvalor de resultado, só pode ocasionar a nulidade do ato, demandada pela Fazenda Pública, quando atingida (C. Civil, art. 105).

\section{IV - BEM JURÍDICO TUTELADO}

7. Toda atividade criminosa ofende interesse do Estado ${ }^{24}$; este é, sempre, sujeito passivo mediato da infração penal, no aspecto parti-

16. NELSON HUNGRIA, Comentários ao Código Penal, v. IX, p. 280.

17. BASILEU GARCIA, Sonegação Fiscal e Falsidade Ideológica Revista dos Tribunais, v. 281, p. 60.

18. V. nota 10 , p. 832 .

19. V. nota 10 , p. 833 .

20. VICENZO MANZINI, Trattato di Diritto Penale Italiano, v. VI, p. 776.

21. V. nota 20 , p. 781.

22. GIAN DOMENICO PISAPIA, Istituzioni di Diritto Penale, p. 293.

23. ALBERTO AURICCHIO, A Simulação no Negocio Juridico, Coimbra, 1964, p. 68.

24. REMO PANNAIN, Gli Elementi Essenziale del Reato, p. 12, nº. 4. 
cular de ver obedecidas as suas leis. Em relação aos delitos contra a ordem tributária aparentemente existe maior dificuldade em fixar qual o bem jurídico a ser tutelado, pois, como bem observa ALFREDO ETCHEVERRY, se esse, em relação a tais crimes, não representar mais que aspectos particularizados de outros bens jurídicos, estará fixada a completa inutilidade de perquirí-lo e a grande dificuldade de protegê-lo ${ }^{25}$.

Entretanto, a par do interesse do Estado em tutelar a não violação de um direito particular, inerente à personalidade, mesmo quando disponível, pode coexistir o de tutelar a ordem tributária ${ }^{26}$. Nada obsta, assim, à existência do poder do Estado em censurar penalmente a desobediência às suas regras jurídicas reguladoras do seu interesse na ordem econômica.

Aliás, entendido o crime contra a ordem tributária como "la violazione del rapporto giuridico tributário per la quale è stabilita una delle pene prevedute dal codice penale ${ }^{\prime 27}$, não ha negar que nos delitos tributários o Estado tutela, também penalmente, o seu direito de impor o tributo. “Oggetto giuridico del reato è il rapporto giuridico risultante dal diritto dello Stato (amministrazione finanziaria) ad imporre il tributo, e dall obligo del cittadino di ottemperare al dovere tributario (oggetto della tutela penale)' ${ }^{\prime 28}$.

\section{V - SUJEITO ATIVO E CONCURSO DE AGENTES}

8. O crime de apropriação de imposto (art. 401) pode ser praticado por qualquer pessoa (tipo comum), enquanto que o de não recolhimento de imposto (art. 401, p. único) é tipo próprio, só podendo ser praticado pelo contribuinte "de jure" (". . . produto de imposto que estava, legalmente, obrigado a recolher), a exemplo do crime de fraude fiscal, previsto no art. 376 do C. Penal de 1969.

Nada impede, porém, o concurso de agentes, seja pela participação, seja pela coautoria. Pode ocorrer a hipotese da autoria mediata, desde que o realizador da figura típica (de qualquer modo instigado, induzido ou coagido por outrem) seja inculpável (por incapacidade de culpa, ausência do potencial conhecimento do injusto ou inexigibilidade de outra conduta).

No caso de a atuação delituosa beneficiar pessoa jurídica, não há como aplicar-se o entendimento de BERNARDINO GONZAGA: "em se tratando de crimes cometidos através de pessoa jurídica, nem todos os co-partícipes serão punidos, mas tão somente aqueles que a essa pessoa jurídica estiverem ligados ${ }^{\prime 29}$. 0 ilustre professor paulista labora em

25. ALFREDO ETCHEVERRY, Objetividade Juridica do Delito Econômico, Revista Brasileira de Criminologia e Direito Penal, nº. 6, p. 99.

26. V. nota 25 , p. 103.

27. V. nota 4 , p. 25 .

28.V. nota 4.

29. JOÃO BERNARDINO GONZAGA, O Crime de Sonegação Fiscal, Revista dos Tribunais, v. 380 , p. 11. 
manifesto equívoco sob dois ângulos: pretendendo limitar o concurso de agentes aos membros da pessoa jurídica e responsabilizar os membros da pessoa jurídica tão só por essa qualidade. "La responsabilità penale è solo responsabilità per azione, per fatto proprio mai per fatto altrui'"30. "Questa particolare modalità di concorso di più in un stesso reato non hà alcuna influenza sulla responsabilità penale dei singoli componenti del collegio. I limiti di tale responsabilità sono egli stessi che derivano dai principi regolari del nostro ramo del diritto, perchè, nell attuale momento storico, la responsabilità penale colletiva constituisce, più che un eresia, una bestemmia giuridica'"31 .

9. O funcionário público que cometa o crime com abuso de seu cargo terá a pena aumentada até a metade, dispõe o art. 423, segunda parte. Diga-se, aliás, que essa norma penal, de caráter geral e ligada à sanção penal, esta absolutamente deslocada no contexto da parte geral, como se a Comissão houvera esquecido de colocá-la na parte geral, já transformada em lei (n0. 7.209, de 11.07.84), a viger a partir de 13.01.85.

\section{VI - SUJEITO PASSIVO}

10. Sujeito passivo imediato é o Estado, pelo aspecto da Fazenda Pública, na arrecadação de imposto, não de taxas de contribuições.

\section{VII - TIPOS OBJETIVOS}

11. A ação cai sobre "I'obbligo tributario" e que é violado "mediante azione contraria alla legge che il tributo impone" ${ }^{\prime \prime 32}$. As formas de conduta são a apropriação (tornar próprio, mudar o ânimo da posse ou da retenção, atuar como titular do direito) ou o desvio (dar finalidade diversa da obrigatória, tirar da rota) do produto de imposto recebido ou retido por empresa. A outra forma de conduta, sob a rubrica de "não recolhimento de imposto", é não fazer entrar, "para os cofres publicos, produto de imposto que estava, legalmente, obrigado a recolher" (art. 401 , p. unico).

Nas condutas tipificadas no "caput", há uma apropriação indébita do produto de imposto, que torna a norma especial quanto à da apropriação indébita (art. 178), com as mesmas penas (espécie e quantidade).

O crime de apropriação de imposto é comissivo, enquanto o de não recolhimento é omissivo (ausência da ação esperada). No tocante ao não recolhimento, a redação é de péssimo gosto: se o crime é omissivo, por força de dispositivo constitucional o administrado só pode estar obrigado a fazer alguma coisa (recolher imposto) em virtude de lei; portanto, se não estava legalmente obrigado a recolher, não comete crime algum. Há evidente e grosseira tautologia.

30. GIUSEPPE BETTIOL, Diritto Penale, p. 210.

31. FRANCESCO ANTOLIZEI, Il Diritto Penale della Società, p. 131.

32. V. nota 4. 
Na forma comissiva, de apropriação ou de desvio, é possível a tentativa. Na forma omissiva, desde que o agente não faça "entrar, para os cofres públicos, produto de imposto que estava, legalmente, obrigado a recolher", na data de lei, cometerá o crime.

A conduta em relação a qualquer outra espécie de tributo que não o imposto (taxas e contribuições) é atípica. Imposto é o tributo destinado a atender, indistintamente, as necessidades de ordem geral da administração pública ${ }^{33}$.

12. Mas há que se alertar para a evidente inconstitucionalidade do disposto no p. único do art. 401.

Diz a Constituição do Estado da União, como direito e garantia individual (art. 153, § 17), que "não haverá prisão civil por dívida, multa ou custas, salvo o caso do depositário infiel ou do responsável pelo inadimplemento de obrigação alimentar, na forma da lei". Ora, o não recolhimento do imposto traduz mera dívida para com a Fazenda Pública. $\mathrm{O}$ contribuinte não sonegou informações. Ao contrário, pode têlas apresentado, se auto-lançado, mas não recolhido o imposto. Não trata, pois, o tipo, de uma conduta censurável objetivamente. Não pagar o que se deve cria um desvalor na esfera obrigacional, jamais na esfera penal. Permite que o Estado execute o contribuinte inadimplente, excutindo, do seu patrimônio, o necessário à satisfação obrigacional, mas não admite a consideração dessa dívida como um desvalor penal de conduta.

\section{VIII - TIPO SUBJETIVO}

13. O tipo subjetivo porta o dolo (vontade livre e consciente de apropriação ou de desvio do dinheiro). O agente deve saber que esse dinheiro é produto de imposto recebido ou retido por empresa. Se o seu dolo não abarcar a qualidade do dinheiro, o crime será o de apropriação indébita comum (art. 178) que, estranhavelmente, mantém a mesma censura penal.

\section{IX - CONSIDERAÇŌES FINAIS}

14. Não me parece que a Comissão que elaborou o Ante-Projeto de Parte Especial do Código Penal tenha agido corretamente, de um ponto de vista de ciência do direito penal, ao instituir os crimes de apropriação de imposto (art. 401) e de não recolhimento de imposto (art. 401, p. único). A redação de ambos é lastimável, criando tipos incertos, sem a seriedade exigida pelo direito penal.

Melhor teria sido a manutenção do crime de fraude fiscal, institu ído pelo art. 376 do C. Penal de 1969, redigido em ótima técnica legislativa e penal, abrangendo todas as hipóteses de conduta constitucional e penalmente pun iveis.

33. RUBENS GOMES DE SOUZA, Compendio de Legislação Tributaria, parte geral, p. 129. 
15. A análise que pretendi fazer sobre os novos tipos penais, agora inclu ídos na rubrica "dos crimes contra a ordem tributária" do Ante-Projeto de Parte Especial do Código Penal, teve a sua base estruturada em trabalho e pesquisa anteriores, publicados na Revista de Direito Público (volume 21) sob o título "Fraude Contra o Fisco". Mas o desenvolvimento e a crítica alcançam outras dimensões, motivo pelo qual posso dizer que é um trabalho e uma pesquisa inéditos, especialmente articulados para as aulas que venho ministrando no curso de Mestrado em Direito do Setor de Ciências Jurídicas da Universidade Federal do Paraná.

Curitiba, novembro de 1984. 